\title{
Evaluation of hand transmitted chainsaw vibrations during wood cutting
}

\author{
Mihai Gabriel Matache ${ }^{1 *}$, Mariana Munteanu', \\ Dragos Nicolae Dumitru ${ }^{1}$ and Mariana Epure $^{1}$ \\ ${ }^{1}$ INMA Bucharest, Testing Department, 013813 Bucharest, Romania
}

\begin{abstract}
Forestry workers are exposed to vibrations from chainsaws which usually are not taken into consideration from the negative impact point of view on their health. However, in time, these vibrations could cause trepidation disease which will affect the worker neuro-muscular and locomotory apparatus. One mean to mitigate the vibrations impact is to measure and determine the worker's exposure level to vibrations during worktime and to dispose the proper measures to reduce their negative impact. Within this paper will be presented experimental results obtained for vibration data recorded on a chainsaw during wood cutting in real life conditions. The equivalent vibration was measured at both front and end handles level and the biggest value was used for calculation of the human exposure level.
\end{abstract}

\section{Introduction}

In forestry there are a lot of works which include the usage of a chainsaw. A chainsaw is a portable engine driven mechanical saw which uses a set of teeth attached to a rotating chain that runs along a guide bar to cut through different materials, usually wood. It is used to do works such as tree cutting, pruning, harvesting of firewood and many other activities. The main source of vibration for a forestry worker is its chainsaw, which usually works at very high rpm and is handheld so the vibrations are transmitted to the hand-arm system through palms and fingers. Workers exposed daily to excessive vibrations transmitted to the handarm system could suffer, on long term, blood flow disorders in fingers and disorders of neurological functions and movements of hand and arm [1].

Hand-arm vibration occur when the handles of a power tool or the surface of a work item oscillates rapidly, and this movement is transmitted into the operator's hand-arm system. Hand-arm vibration (HAV) is usually felt by operators who regularly use handheld equipment like chainsaws, drills, rototillers and trimmers [2]. The factors which influence the effect of vibrations on human body are the oscillations intensity, the distance between the vibration source and the individual, the body position, the period of time and the exposure level, the vibration frequency spectrum and their direction. The most adverse effects are produced by vibration of frequency close to the first order vibration of the human body $(6-9 \mathrm{~Hz})$.

\footnotetext{
* Corresponding author: gabimatache@yahoo.com
} 
The European Directive 2002/44/CE on the minimum health and safety requirements regarding the exposure of workers to the risks arising from vibrations impose specific requirements for the safety of workers exposed to mechanical vibrations. Through this directive two exposure indicators for the hand-arm system transmitted vibrations have been defined: the action value and the exposure limit value. The overcoming of these two values lead to a set of obligations. The daily exposure action value on the hand-arm system, standardised to an eight-hour reference period, A (8) shall be $2,5 \mathrm{~m} / \mathrm{s}^{2} \mathrm{RMS}$, while the daily exposure limit value, standardised to an eight-hour reference period, shall be $5 \mathrm{~m} / \mathrm{s}^{2} \mathrm{RMS}$ [3].

The method to assess the exposure level to vibrations is standardised by EN ISO 5349 Mechanical vibration- Measurement and evaluation of human exposure to hand-transmitted vibration [4]. Based on this, various researchers studied the hand-arm transmitted vibration level by various handheld tools, usually by direct measurements during work, using three axes accelerometers mounted on the handles $[5,6,7]$. The obtained results differed in function of the testing conditions and of the used power tools. Also, there were conducted theoretical and experimental researches in order to forecast the exposure risk for workers subjected to HAV [8].

Within this paper are presented the experimental results obtained for the human exposure level during wood cutting with a chainsaw. The weighted vibrations were measured using an orthogonal reference system in full load operation mode and were used to assess the exposure level during a typical day of work.

\section{Material and method}

Tests were performed on the PTR 565 type chain-saw. The chainsaw was driven by a 54 $\mathrm{cm}^{3}, 2$ strokes gas engine. The weighted vibration testing method was based on ISO 22867 - Forest Machines, Vibration Testing Code for hand-held portable machines which provides general specifications for vibration measurement of hand-held machines [9].

Vibrations were measured as accelerations in $\mathrm{m} / \mathrm{s}^{2}$. The weighted accelerations on the three perpendicular directions of the orthogonal measuring system: $a_{h w x}, a_{h w y}, a_{h w z}$ were measured using two 3-axis accelerometers for both front and rear handles of the chainsaw. The total vibration value, $a_{h w v}$ was computed for each handle.

$$
a_{h w v}=\left[\left(a_{h w x}^{2}+a_{h w y}^{2}+a_{h w z}^{2}\right)\right]^{\frac{1}{2}}
$$

The daily exposure level $\mathrm{A}(8)$ for a reference period $\mathrm{T}_{0}$ of 8 hours was obtained from total vibration values $a_{h w v}$ and the daily exposure time $T$.

$$
A(8)=a_{h w v} \sqrt{\frac{T}{T_{0}}}
$$

The three-axes accelerometers model 356B10 from PCB Piezotronics were mounted on the front and rear handle of the chainsaw using wax. For data recording was used a 16 channels SIRIUS data acquisition system produced by DEWESoft. The accelerometers calibration was performed using a Bruel\&Kjaer calibration exciter 4294 type with a $10 \mathrm{~m} / \mathrm{s}^{2}$ RMS vibration level at $159.2 \mathrm{~Hz}$. The digital weighing filter to the vibration data was applied directly during measurements and formula (1) was used to calculate the total vibration level. The experiments were performed on trees with diameters of approximately $0.4 \mathrm{~m}$, which were cut down due to their weak condition. The chainsaw was accelerated 
from idle to full throttle and kept there until the work was done. The data acquisition periods were from the beginning to the finishing of the cut. For measuring the weighted vibration level were recorded 10 replicas of the cutting experiments and the mean value of the vibrations was reported. In order to estimate de daily exposure time to vibrations, the real exposure time was timed using a chronometer during a typical cutting tree cycle and then was multiplied by the number of cut trees during an 8 -hour work day.

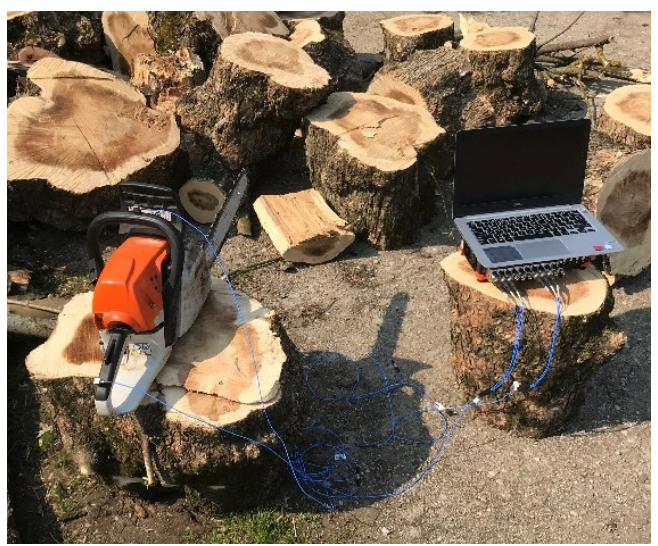

Fig. 1 Test setup for vibration measurement.

\section{Results}

In figure 2 are presented the unweighted time series vibration measured on the front handle of the chainsaw $a_{h x}, a_{h y}, a_{h z}$ during one tree cutting experiment. The OY axis corresponds to the longitudinal median plane of the saw, OX axis is perpendicular on the median plane and $\mathrm{OZ}$ axis is perpendicular on the surface of the soil with the machine in normal position. During work, these positions were turned by approximately 60-70 degrees, in a rolling motion.

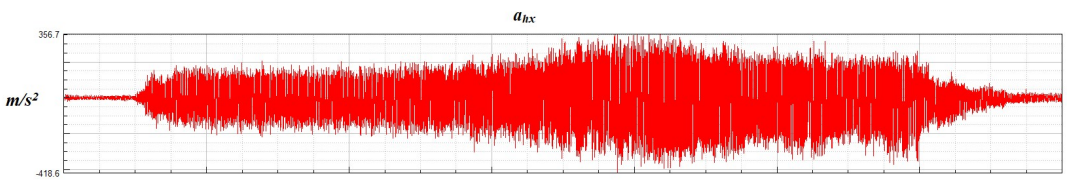

$a_{h y}$

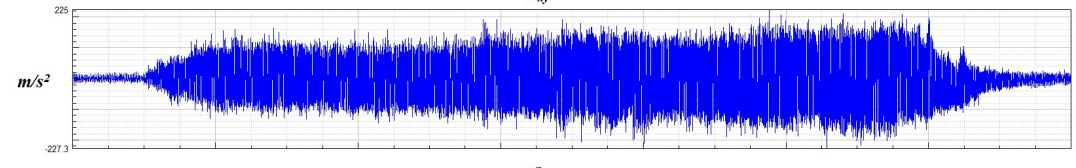

$a_{h z}$

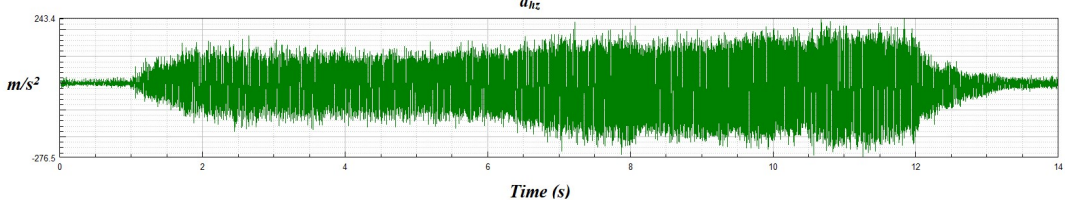

Fig. 2 Front handle chain-saw vibrations $a_{h x}, a_{h y}, a_{h z}$. 
In figure 3 are graphically displayed the same vibrations, this time zoomed in order to better display their real oscillations. The sampling frequency for data acquisition was set at $10 \mathrm{kHz}$, so that all relevant information to be recorded.
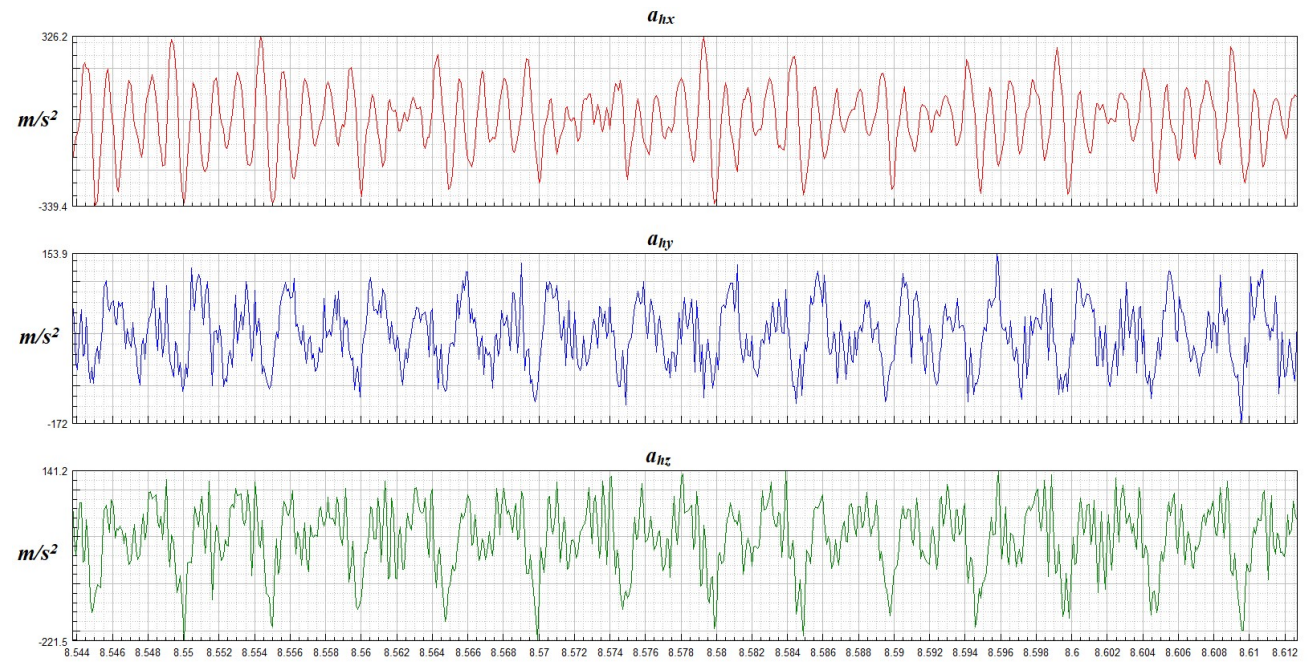

Time $(s)$

Fig. 3 Front handle chain-saw vibrations $a_{h x}, a_{h y}, a_{h z}$-zoom in.

In figure 4 is presented the frequency spectrum histogram, computed for the same set of data presented in figure 1 . We can observe the first order frequency around $200 \mathrm{~Hz}$, which is the same as that of the chainsaw full throttle $12000 \mathrm{rpm}$. The other frequencies correspond to harmonics of the first one. There frequency range presented was limited to $1250 \mathrm{~Hz}$, because of the applied hand-arm weighting filter, which also works up to the same limit.
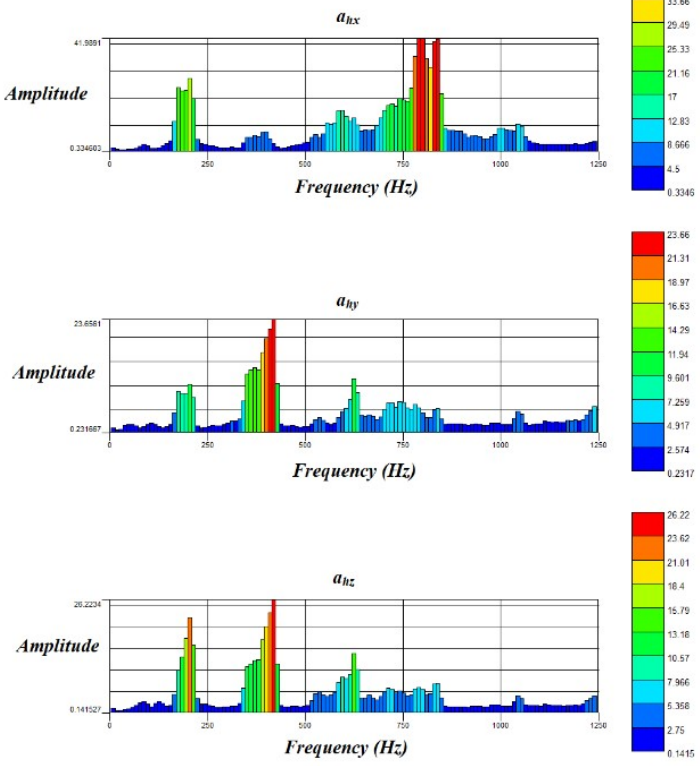

Fig. 4 Frequency spectrum for the chainsaw vibrations. 
By applying the frequency weighing filter, the amplitude of vibrations dropped significantly. In figure 5 is presented graphically the applied weighing filter $\mathrm{W}_{\mathrm{h}}$ according to EN 5349 and in figure 6 are presented the same vibrations as in figure 1, after weighting.

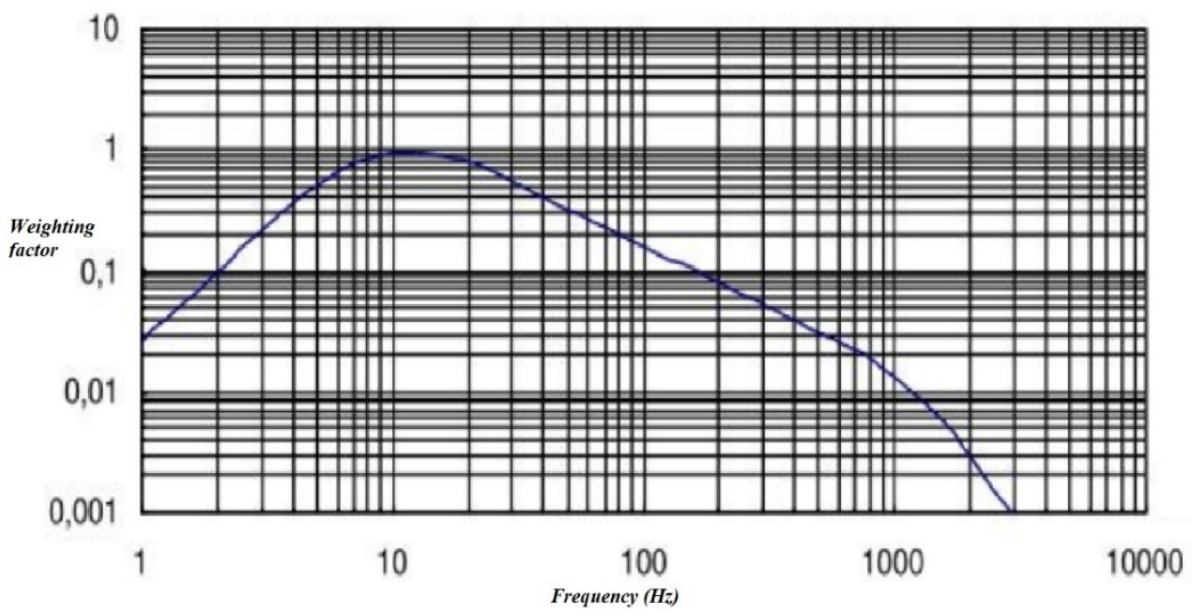

Fig. 5 Weighting filter $W_{h}$.
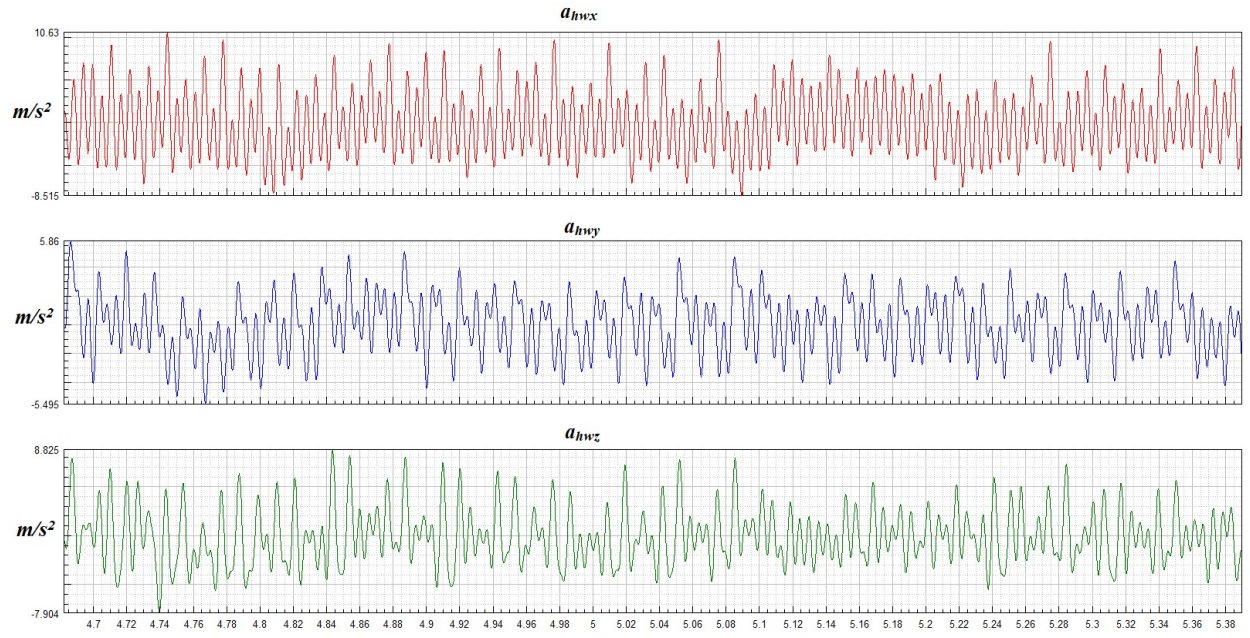

Time (s)

Fig. 6 Front handle chain-saw weighted vibrations $a_{h w x}, a_{h w y}, a_{h w z}-$ zoom in.

In table 1 are presented the values obtained for the total vibration values $a_{h w v}$ obtained for all the 10 replicas of the tree cutting experiment, both for front and rear handle and their mean value after computing the average. 
Table1. Total weighted vibration values for front and rear handles of the chainsaw

\begin{tabular}{|c|c|c|}
\hline Crt. no & $\begin{array}{c}\text { Front handle }-\boldsymbol{a}_{\boldsymbol{h w v}} \\
\left(\mathbf{m} / \mathbf{s}^{\mathbf{2}}\right)\end{array}$ & $\begin{array}{c}\text { Rear handle }-\boldsymbol{a}_{\boldsymbol{h w v}} \\
\left(\mathbf{m} / \mathbf{s}^{\mathbf{2}}\right)\end{array}$ \\
\hline 1. & 4.84 & 4.24 \\
\hline 2. & 4.32 & 3.88 \\
\hline 3. & 4.98 & 4.33 \\
\hline 4. & 5.02 & 4.41 \\
\hline 5. & 5.21 & 4.48 \\
\hline 6. & 4.61 & 4.03 \\
\hline 7. & 4.58 & 4.01 \\
\hline 8. & 4.14 & 3.66 \\
\hline 9. & 4.35 & 3.78 \\
\hline 10. & 4.78 & 4.03 \\
\hline Mean value & $\mathbf{4 . 6 8}$ & $\mathbf{4 . 0 9}$ \\
\hline $\begin{array}{l}\text { Standard } \\
\text { deviation }\end{array}$ & $\mathbf{0 . 3 4}$ & $\mathbf{0 . 2 7}$ \\
\hline
\end{tabular}

Because of the different widths of the tree trunks the duration of the experiments was also different. However, the total vibration results scatter between the experiments was of $7.26 \%$ for the front handle vibration and $6.6 \%$ for the rear one. This scatter under $10 \%$ assures us that the results are representative for the chosen work and could be used for the assessment of the human exposure level to vibrations during chainsaw handling.

Further on, the tree felling cycles periods for each experiment were timed. The felling cycle was considered as being formed of 4 effective cutting periods: the superior wedge cutting period, the inferior wedge cutting period, rest of the trunk cutting period and trimming of the felled tree. The idle engine chainsaw handling was omitted. In table 2 are presented the results obtained after time measuring of the cutting periods.

Table2. Tree cutting felling cycle periods

\begin{tabular}{|c|c|c|c|c|c|}
\hline Crt. no & $\begin{array}{c}\text { Superior } \\
\text { wedge cutting } \\
\text { period (s) }\end{array}$ & $\begin{array}{c}\text { Inferior } \\
\text { wedge } \\
\text { cutting } \\
\text { period (s) }\end{array}$ & $\begin{array}{c}\text { Trunk } \\
\text { cutting } \\
\text { period (s) }\end{array}$ & $\begin{array}{c}\text { Trimming } \\
\text { (s) }\end{array}$ & $\begin{array}{c}\text { Total time } \\
\text { (s) }\end{array}$ \\
\hline 1. & 6 & 5 & 15 & 624 & 650 \\
\hline 2. & 6 & 6 & 17 & 748 & 777 \\
\hline 3. & 5 & 5 & 14 & 657 & 681 \\
\hline 4. & 7 & 5 & 16 & 504 & 532 \\
\hline 5. & 6 & 6 & 15 & 687 & 714 \\
\hline 6. & 8 & 6 & 18 & 724 & 756 \\
\hline 7. & 7 & 7 & 18 & 726 & 758 \\
\hline 8. & 6 & 4 & 14 & 806 & 830 \\
\hline 9. & 5 & 4 & 14 & 705 & 728 \\
\hline 10. & 6 & 6 & 15 & 741 & 768 \\
\hline Mean value & $\mathbf{6 . 2 0}$ & $\mathbf{5 . 4 0}$ & $\mathbf{1 5 . 6 0}$ & $\mathbf{6 9 2 . 2 0}$ & $\mathbf{7 1 9 . 4 0}$ \\
\hline $\begin{array}{c}\text { Standard } \\
\text { deviation }\end{array}$ & $\mathbf{0 . 9 2}$ & $\mathbf{0 . 9 7}$ & $\mathbf{1 . 5 8}$ & $\mathbf{8 3 . 0 7}$ & $\mathbf{8 3 . 1 7}$ \\
\hline
\end{tabular}

The mean time consumed for one tree felling was considered to be around 20 minutes, fact which means that during a work day could be cut down around 24 trees. This means that the daily exposure time $\mathrm{T}$ for cutting the tree was of 17265.6 seconds, or 4.796 hours.

Applying formula (2) for calculation of daily exposure level in which we considered the mean values reported in tables 1 for total vibration, we obtained $3.60 \mathrm{~m} / \mathrm{s}^{2}$ for the front 
handle and $3.15 \mathrm{~m} / \mathrm{s}^{2}$ for the rear handle, values which are in the intermediate situations between the level of action and the exposure limit values $\left(2,5 \mathrm{~m} / \mathrm{s}^{2}<\mathrm{A}(8)<5,0 \mathrm{~m} / \mathrm{s}^{2}\right)$.

\section{Conclusions}

After the vibration measuring experiments performed for the wood cutting work with a chainsaw were observed high amplitude vibrations. The maximum weighted acceleration on the handles of the chainsaw showed values which could damage on long term the operator's state of health, fact that suggest the need of intervention and health monitoring.

The results for the daily exposure level of the chainsaw operator to vibrations for both handles of the equipment were located between the daily exposure action value on the hand-arm system, standardised to an eight hour reference period, $\mathrm{A}(8)=2,5 \mathrm{~m} / \mathrm{s}^{2} \mathrm{RMS}$, and the daily exposure limit value, standardised to an eight-hour reference period, of $5 \mathrm{~m} / \mathrm{s}^{2}$ RMS, imposed by European Directive 2002/44/CE.

This work has been funded by the European Social Fund from the Sectoral Operational Programme Human Capital 2014-2020, through the Financial Agreement with the title "Scholarships for entrepreneurial education among doctoral students and postdoctoral researchers (Be entrepreneur!)", Contract no. 51680/09.07.2019 - SMIS code: 124539. $>>$

\section{References}

1. Forouharmajd F, Yadegari M, Ahmadvand M, Forouharmajd F, Pourabdian S. Handarm Vibration Effects on Performance, Tactile Acuity, and Temperature of Hand. J Med Signals Sens. 2017;7(4):252-260.

2. Vladimir Šinik, Željko Despotović, Slobodan Janković, "Exposure to hand-arm vibration, tools for calculating daily exposures and measurment", V International Conference „Ecology of Urban Areas“ 2016, Zrenjanin, 30 september, 2016

3. Directive 2002/44/EC of the European Parliament and of the Council of 25 June 2002 on the minimum health and safety requirements regarding the exposure of workers to the risks arising from physical agents (vibration) (sixteenth individual Directive within the meaning of Article 16 (1) of Directive 89/391/EEC)

4. EN ISO 5349 Mechanical vibration- Measurement and evaluation of human exposure to hand-transmitted vibration.

5. Monarca D., Biondi P., Cecchini M., Santi M., Guerrieri M., Colantoni A., Colopardi F., Transmission of vibrations from portable agricultural machinery to the Hand-Arm System (HAV): risk assessment and definition of exposure time for daily action and exposure limits, International Conference: September 15-17, 2008 Ragusa - Italy, "Innovation Technology to Empower Safety, Health and Welfare in Agriculture and Agro-food Systems"

6. Sorica E., Vladut V., Cardei P., Sorica C., Bracacescu C., 2017. Comparative analysis of the noise and vibration transmitted to the operator by a brush cutter, Acoustics and Vibration of Mechanical Structures-AVMS-2017: Proceedings of the 14th AVMS Conference, pp. 165-172.

7. Búrdalo Salcedo G., Ortiz E., et. al. (2014). Hand-Arm Vibration (HAV) produced by pneumatics screwdrivers used in a wind power company, International Symposium on Occupational Safety and Hygiene - SHO 2014

8. Vasilescu G. D., Ghicioi E., Simion S., Pasculescu V. (2013). Model for Forecasting the Exposure Risk of Workers to Hand-Arm Occupational Vibrations. Applied Mechanics and Materials, 430, 276-280.

9. EN ISO 22867 - Forestry and gardening machinery. Vibration test code for portable hand-held machines with internal combustion engines. Vibration on the handles. 